\title{
Weight gain potential affects pregnancy rates in bovine embryo recipients raised under pasture conditions
}

\author{
Carlos Antonio de Carvalho Fernandes ${ }^{1} \cdot$ Miller Pereira Palhao ${ }^{1}$. \\ Ana Cristina Silva Figueiredo ${ }^{1}$. Josiane Rossi Ribeiro ${ }^{1} \cdot$ Fabyano Fonseca e Silva $^{2}$. \\ Joao Henrique Moreira Viana ${ }^{3}$
}

Received: 20 April 2015 / Accepted: 24 September 2015 / Published online: 2 October 2015

(C) Springer Science+Business Media Dordrecht 2015

\begin{abstract}
The aim of the present study was to evaluate the effect of differences in body weight gain after embryo transfer on the pregnancy rates of crossbred heifers used as recipients and raised under a grazing system. The study was performed during the dry (April to September) and the rainy (October to March) seasons. The embryos transferred were produced by in vitro fertilization. The body weight of each recipient was measured immediately before the embryo transfer and 23 to 25 days later, when the diagnosis of pregnancy was performed by ultrasonography. The associations among initial body weight (IBW), daily body weight gain (DWG), season, and pregnancy rate were evaluated using a logistic procedure that included the effect of the IBW, season, and linear and quadratic effects of the DWG. Altogether, there was no effect of season and pregnancy rates did not change between the dry and rainy seasons ( 42.3 vs. $45.8 \%$, respectively; $P>0.05$ ). However, the pregnancy rate was greater in the recipients with daily body weight gains over $250 \mathrm{~g} /$ day, regardless of the season. In addition, the pregnancy rate of the recipients was better $(P<0.04)$ explained by a logistic regression model that included the linear and quadratic effects of the DWG. The probability of each heifer to become pregnant according to DWG is explained by the follow equation: $P(y=$

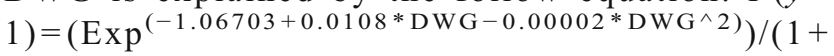

Carlos Antonio de Carvalho Fernandes carlos@biotran.com.br

1 Department of Veterinary Medicine, University José do Rosário Vellano, Alfenas, MG 37130-000, Brazil

2 Department of Animal Science, Federal University of Viçosa, Viçosa, MG 36570-000, Brazil

3 Embrapa Dairy Cattle Research Center, Brazilian Agricultural Research Corporation, Juiz de Fora, MG 36038-330, Brazil

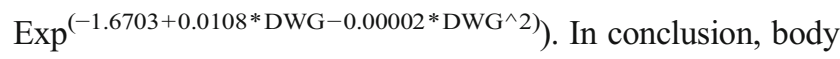
weight gain potential is a critical factor for the pregnancy rates of in vitro embryo recipients managed under grazing systems.

Keywords Body condition score $\cdot$ Cattle $\cdot$ Embryo transfer . Nutrition

\section{Introduction}

Brazil is the world leader in bovine embryo production using the in vitro fertilization (IVF) technique. The overall production exceeded 350,000 embryos in 2011, which represents more than one third of all bovine embryos produced in the world (Viana et al. 2012). Unfortunately, while the use of the IVF technique has increased in numbers, the performance indexes, especially the pregnancy rate of the embryo recipients, did not significantly change in recent years (Viana et al. 2010).

Nutrition is a well-known factor that affects reproductive performance, both in natural breeding and when assisted reproductive technologies, such as artificial insemination and embryo transfer, are used (Robinson et al. 2006). Nutritionally induced metabolic changes affect a range of parameters related to reproduction, including the intrafollicular environment (Leroy et al. 2011), oocyte quality and developmental potential (Adamiak et al. 2006), progesterone production (Green et al. 2005), uterine function and health (Zhu et al. 2007; Wathes et al. 2007), and embryo survival and pregnancy maintenance in the recipients (Jones and Lamb 2008).

In raising systems in which embryo recipients are kept under grazing conditions, a typical situation in many tropical countries, forage availability and quality are important issues to be considered. During the year, there is a significant variation in the biomass available for pasture, as well as in the grass 
quality and digestibility (Rueda et al. 2003), related to seasonal changes in the length of daylight and amount of rain. In the dry season, the low volume and protein levels of the grass may not meet the nutritional requirements for maintenance of the animals and thus reduce the body weight gain or even cause body weight loss and a negative variation of the body condition score (BCS) (Funston et al. 2010).

The performance of each animal in a grazing system, however, is affected not only by forage availability but also by its own genetic potential and metabolic efficiency (Kawashima et al. 2007). Most embryo recipient herds used in large-scale in vitro embryo production (IVEP) programs in Brazil are formed by crossbred cattle (Viana et al. 2010), sometimes of unknown Bos indicus $\times$ Bos taurus blood share and therefore of unknown nutritional requirements. Much attention was given to the effects of BCS on the pregnancy rate of embryo recipients, but the interplay of body weight gain potential and likelihood of pregnancy is not well understood. The aims of the present study were to evaluate the effect of differences in body weight gain after embryo transfer on the pregnancy rates of crossbred heifers used as recipients of embryos produced in vitro, and to determine the minimum body weight gain level for a good performance of the embryo recipients kept exclusively under grazing systems.

\section{Materials and methods}

\section{Location, animals, estrous synchronization, embryo production, and transfer}

The study was performed during one year in a farm located in the southern region of Minas Gerais State. The regional climate is Cw according to Koepen's system (Peel et al. 2007). The dry season (April to September) is characterized by an average precipitation of $470 \mathrm{~mm}$ and low grass availability, while the rainy season (October to March) is characterized by an average precipitation of $1930 \mathrm{~mm}$ and high grass availability. Crossbred heifers $($ B. taurus $\times$ B. indicus $)$, nulliparous, with initial body weight (IBW) ranging from 328 to $426 \mathrm{~kg}$ were used as embryo recipients. The average BCS were $3.3 \pm$ 0.6 and $3.4 \pm 0.6$ during the dry and rainy seasons, respectively, in a 1 to 5 scale (Isensee et al. 2014). The heifers were kept under a grazing system (Brachiaria brizanta), with ad libitum access to water and to a mineral mixture. During the rainy season, the stocking rate used was 1.3 animal units/hectare (AU/ha), while during the dry season, the rate was reduced to $1.1 \mathrm{AU} / \mathrm{ha}$. The heifers used in each season were standardized before undergoing the synchronization protocol to have a body weight $>300 \mathrm{~kg}$ and show cyclic ovarian luteal activity.

The estrous was synchronized by an intramuscular injection of $0.530 \mathrm{mg}$ sodium cloprostenol (Ciosin, MSD Saúde Animal, São Paulo, SP, Brazil). The heifers showing estrous behavior between 2 and 4 days after the injection were later evaluated (on average 7 days after estrus) by ultrasonography (Aquila Vet, Esaote, Genova, Italy). Heifers with ovarian corpus luteum (CL) were selected as embryo recipient. Embryos $(n=484)$ were produced in vitro by the same IVEP laboratory (Biotran Biotecnologia e Treinamento LTDA, Alfenas, MG, Brazil), using oocytes recovered by ovum pick-up from Gir donors and fertilized with sex-sorted semen from Gir bulls, as described elsewhere (Camargo et al. 2010). Briefly, COCs were washed twice in TCM199 plus HEPES medium and matured in vitro in TCM199 (Invitrogen, Gibco BRL, Grand Island, NY, USA) with $10 \%$ inactive estrous cow serum and $20 \mathrm{mg} / \mathrm{mL}$ of FSH (Pluset, Hertape Calier, Juatuba, MG, Brazil) for $22 \mathrm{~h}$ in a humidified atmosphere of $5 \% \mathrm{CO}_{2}$ and $38.8^{\circ} \mathrm{C}$ in air. In vitro fertilization was performed in $100-\mu \mathrm{L}$ drops of fertilization medium supplemented with $20 \mu \mathrm{g} / \mathrm{mL}$ of heparin and $6 \mathrm{mg} / \mathrm{mL}$ of fatty acid-free bovine serum albumin (BSA) fraction $\mathrm{V}$, covered with mineral oil, for $18 \mathrm{~h}$ in a humidified atmosphere of $5 \% \mathrm{CO}_{2}$ and $38.8{ }^{\circ} \mathrm{C}$ in air. Oocytes were fertilized in vitro using $2 \times 10^{6}$ spermatozoa/ $\mathrm{mL}$, separated by centrifugation in a Percoll discontinuous gradient. After fertilization, oocytes were partially stripped by mechanical pipetting in TALP medium until only one or two cumulus cell layers remained. Groups of 12-18 presumptive zygotes with their respective cumulus cells were then cultured in $50 \mu \mathrm{L}$ SOF medium supplemented with $10 \%$ FCS and $1 \mathrm{mg} / \mathrm{mL}$ BSA, covered with mineral oil. Embryo culture was performed in a humidified atmosphere of $5 \% \mathrm{CO}_{2}$ and $38.8^{\circ} \mathrm{C}$ in air. Half of the medium was replaced at $72 \mathrm{~h}$ post-insemination (hpi). Only embryos developed up to blastocyst or expanded blastocyst stages and classified as quality grade I were transferred. All procedures of OPU and all embryo transfers were performed by the same technician.

\section{Experimental design}

The association of daily body weight gain (DWG) after embryo transfer and pregnancy rate was studied during the dry (April to September) and rainy (October to March) seasons. Both evaluations were done on the day of embryo transfer and 23-25 days later, on the day of pregnancy diagnosis performed by ultrasonography. Daily body weight gain was calculated based on the difference between final and initial body weight of the heifers during this period. The recipients were weighed with an electronic weighing device.

\section{Data analysis}

The influence of DWG and season on the pregnancy rate was also evaluated. For this, a generalized linear model for binary trait (pregnant and non-pregnant) was used, using the LOGISTIC procedure of SAS software. This model was selected using a stepwise method and considered the IBW, 
season, and linear and quadratic DWG effects. The pregnancy rates were compared between seasons with the chi-squared test. The statistical significance was determined based on a $P$ value of 0.05 . The analyses were performed with SAS version 9.1.3 (SAS Institute Inc., Cary, NC).

\section{Results}

There was no difference $(P>0.05)$ in pregnancy rates among embryo developmental stages, and these data were pooled. The initial average body weight of the recipients was 346.5 $\pm 33.4 \mathrm{~kg}$. There was no difference $(P>0.05)$ in the initial body weight of the recipients between periods (rainy and dry seasons). The overall pregnancy rate was similar between the rainy and dry seasons ( 42.3 vs. $45.8 \%$, respectively; $P>0.05$ ).

In this experimental approach, where heifers were firstly standardized before undergoing hormone protocols for embryo transfer (ET), the effects of season and IBW on pregnancy rate were not significant ( $P>0.9$ and $>0.3$, respectively). Therefore, the pregnancy rate of the recipients was better described $(P<0.03)$ by a regression model that included the linear and quadratic effects of the DWG (Fig. 1). The probability for each heifer to become pregnant according to DWG ( $g /$ day) can be explained by the following equation: $P(y=$ $1)=\left(\operatorname{Exp}^{\left(-1.6703+0.0108 * \mathrm{DWG}-0.00002 * \mathrm{DWG}^{\wedge} 2\right)}\right) /(1+$

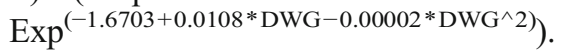

\section{Discussion}

The detrimental effects of the negative energy balance on reproduction are well documented in cattle (Robinson et al.
2006). Most of these effects, however, are directly related to reduction in the oocyte quality or in the embryo developmental potential; therefore, the importance of the relationship between nutrition and the uterine microenvironment may be underestimated. Embryo recipients are an interesting model to evaluate this, as long as embryo quality is standardized. In the present study, we evaluated the differences in pregnancy rates according to the daily body weight gain in the recipients of in vitro-produced embryos. These recipients were raised under pasture conditions, so we initially hypothesized that pregnancy rates would be affected by season (dry or rainy). Our main finding, however, was that pregnancy rates were affected by the magnitude of the daily body weight gain between embryo transfer and pregnancy diagnosis, regardless of the season or the initial body weight of the heifers.

In the present study, we evaluated recipients during the expected early pregnancy (from embryo transfer to pregnancy diagnosis, i.e., from day 7 to approximately day 30 ) because this is a critical phase for the establishment and maintenance of pregnancy, which may be disturbed by several environmental effects, including nutrition. The cross-talk between trophoblastic and endometrial epithelial cells plays a key role in corpus luteum maintenance (Spencer et al. 2006). On the other hand, any change in the metabolic route that leads to the endometrial production of $\mathrm{PGF}_{2} \alpha$, including those induced by changes in metabolites in the maternal blood, can affect embryo survival (Funston et al. 2010). After the maternal recognition of pregnancy, which occurs in cattle on approximately day 16 after conception (Lonergan 2011), the metabolism of the pregnant female gradually changes and supports the maintenance of pregnancy. Thus, further nutritional variations have less impact on embryo/fetus development. Moreover, we evaluated the pregnancy rates of recipients receiving in vitro-
Fig. 1 Logistic regression of the probability of pregnancy according to daily body weight gain (DWG). The quadratic function of the DWG $(\times$ variable in the equation) better $(P<0.04)$ explained the probability of the pregnancy $(P(y=1)$ in the equation). The term $\operatorname{Exp}$ in the equation means exponential function. The central stroke line represents the behavior of the probabilities, and the lateral weak lines represent a $95 \%$ confidence interval

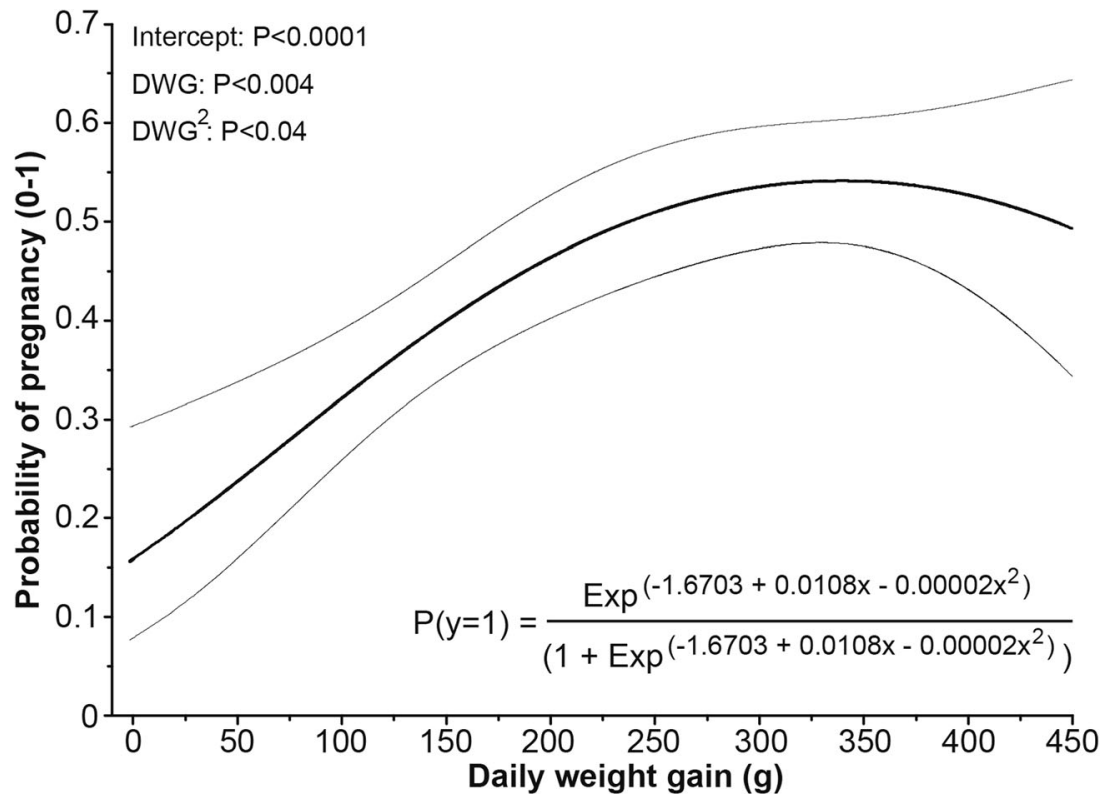


produced embryos. These embryos have a lower developmental potential, when compared to those produced in vivo (Machado et al. 2013), and therefore are a very sensitive model for evaluating factors that affect the likelihood of pregnancy in the recipients.

In the present study, the individual variation in the potential to reach DWG over $250 \mathrm{~g} /$ day, regardless of the season, was the main factor affecting pregnancy rates. The regression analysis showed that pregnancy rate increases as DWG increases up to $350 \mathrm{~g}$ /day and drops thereafter, suggesting this is a threshold for optimal pregnancy rates in embryo recipients, regardless of the season (Fig. 1). The individual variation observed in DWG under the same conditions is not unusual for a $B$. taurus $\times B$. indicus crossbred herd and may be related to differences in the genetic background for metabolic efficiency, growth potential, or even resistance to tropical environmental conditions. Thus, pregnancy rates in embryo recipients raised under pasture conditions could be improved by the selection of heifers according to their body weight gain potential under these conditions.

The detrimental effects of the metabolic changes related to a negative energy balance on the reproductive physiology and performance are well documented (reviewed by Diskin et al. 2003), especially near ovulation and in the early pregnancy (Robinson et al. 2006). Zhu et al. (2007) demonstrated that the low availability of nutrients in maternal blood during the early pregnancy could disrupt the cross-talk between the embryo and the mother, even before implantation. In extreme situations, insufficient intake may impair the later stages of follicular development and anestrus is observed in cattle undergoing prolonged periods of under-nutrition (Bossis et al. 2000). Alternatively, a positive energy balance was associated with an increased likelihood of a shorter calving to conception interval in lactating cows (Patton et al. 2007).

In cattle herds managed under grazing systems, it could be expected that the seasonal variation in pasture quality would have a major importance in reproductive outcomes. The negative energy balance and body weight loss in the dry period, or the positive energy balance in the rainy period, would cause reduction or improvement in pregnancy rates, respectively, as previously reported (Crowe 2008; Tinoco et al. 2012). In the current study, however, seasonal changes in the grass quality and availability were partially compensated by the different stocking rates used and by the expected low nutritional requirements of the heifers, and consequently, there was no effect of season on the overall pregnancy rates. This result suggests that changes in the stocking rate can minimize the detrimental effects of decreased grass availability on reproductive performance.

The evaluation of BCS is an important tool for reproductive management because it reflects the amount of body fat reserve (Isensee et al. 2014). This is the easiest approach to evaluate the energy balance in cattle; however, because it is a subjective method, slight variation can be undetectable (Crowe 2008). In our study, the short period between evaluations resulted in relatively small differences in the total body weight (less than $2 \%$ ) and consequently in the BCS. Thus, scoring of body condition is not an approach sensitive enough to detect the small changes in body weight that can potentially affect pregnancy rates, as shown in the present study.

In conclusion, body weight gain potential is critical for the pregnancy rates of embryo recipients managed under grazing systems. Daily body weight gains over $250 \mathrm{~g}$ between embryo transfer and pregnancy diagnosis are necessary to optimize pregnancy rate in embryo recipients kept in grazing systems, regardless of the season of the year.

Acknowledgments This research was supported by grants from the National Council for Scientific and Technological Development (CNPq, Brazil) and FAPEMIG. The authors thank Biotran LTDA for technical assistance and animal handling.

Conflict of interest The authors declare that they have no competing interests.

Statement of animal rights This study was approved by the Ethics in the Use of Animals Committee of the University José do Rosário Vellano-UNIFENAS, Alfenas, MG. The manuscript does not contain clinical studies or human patient data.

\section{References}

Adamiak, S.J., Powell, K., Rooke, J.A., Webb, R., Sinclair, K.D., 2006. Body composition, dietary carbohydrates and fatty acids determine post-fertilisation development of bovine oocytes in vitro. Reproduction, 131:247-258. DOI: 10.1530/rep.1.00871

Bossis, I., Wettemann, R.P., Welty, S.D., Vizcarra, J., Spicer, L.J., 2000. Nutritionally induced anovulation in beef heifers: ovarian and endocrine function during realimentation and resumption of ovulation. Biology of Reproduction, 62:1436-1444. DOI: 10.1095/ biolreprod62.5.1436

Camargo, L.S., Freitas, C., de Sa, W.F., de Moraes Ferreira, A., Serapiao, R.V., Viana, J.H., 2010. Gestation length, birth weight and offspring gender ratio of in vitro-produced Gyr (Bos indicus) cattle embryos. Animal Reproduction Science, 120:10-5. DOI: 10.1016/j. anireprosci.2010.02.013.

Crowe, M.A. 2008. Resumption of ovarian cyclicity in post-partum beef and dairy cows. Review Article. Reprod Dom Anim 43 (Suppl. 5), 20-28. DOI: 10.1111/j.1439-0531.2008.01210.x.

Diskin, M.G., Mackey, D.R., Roche, J.F., Sreenan, J.M., 2003. Effects of nutrition and metabolic status on circulating hormones and ovarian follicle development in cattle. Animal Reproduction Science, 78: 345-370. DOI:10.1016/S0378-4320(03)00099-X.

Funston, R.N., Larson, D.M., Vonnahme, K.A., 2010. Effects of maternal nutrition on conceptus growth and offspring performance: Implications for beef cattle production. Journal of Animal Science, 88:205-215. DOI: 10.2527/jas.2009-2351.

Green, M.P., Hunter, M.G., Mann, G.E., 2005. Relationships between maternal hormone secretion and embryo development on day 5 of pregnancy in dairy cows. Animal Reproduction Science, 88:179189. DOI:10.1016/j.anireprosci.2004.12.007. 
Isensee, A., Leiber, F., Bieber, A., Spengler, A., Ivemeyer, S., Maurer, V., Klocke, P. 2014. Comparison of a classical with a highly formularized body condition scoring system for dairy cattle. Animal, 8(12): 1971-1977. DOI: 10.1017/S1751731114001888.

Jones, A.L. and Lamb, G.C., 2008. Nutrition, synchronization, and management of beef embryo transfer recipients. Theriogenology, 69: 107-15. DOI:10.1016/j.theriogenology.2007.09.004

Kawashima, C., Sakaguchi, M., Suzuki, T. Sasamoto, Y., Takahashi, Y., Matsui, M., Miyamoto, A. 2007. Metabolic profiles in ovulatory and anovulatory primiparous dairy cows during the first follicular wave postpartum. Journal of Reproduction and Development, 53:113-120. DOI: http://doi.org/10.1262/jrd. 18105.

Leroy, J.L., Rizos, D., Sturmey, R., Bossaert, P., Gutierrez-Adan, A., Van Hoeck, V., Valckx, S., Bols, P.E., 2011. Intrafollicular conditions as a major link between maternal metabolism and oocyte quality: a focus on dairy cow fertility. Reproduction Fertility and Development, 24:1-12. DOI: 10.1071/RD11901.

Lonergan, P., 2011. Influence of progesterone on oocyte quality and embryo development in cows. Theriogenology, 76:1594-601. DOI: 10 . 1016/j.theriogenology.2011.06.012.

Machado, G.M., Ferreira, A.R., Guardieiro, M.M., Bastos, M.R., Carvalho, J.O., Lucci, C.M., Diesel, T.O., Sartori, R., Rumpf, R., Franco, M.M., Dode, M.A., 2013. Morphology, sex ratio and gene expression of day 14 in vivo and in vitro bovine embryos. Reproduction Fertility and Development, 25:600-608. DOI: 10. 1071/RD11282.

Patton, J., Kenny, D.A., McNamara, S., Mee, J.F., O’Mara, F.P., Diskin, M.G., Murphy, J.J., 2007. Relationships among milk production, energy balance, plasma analytes, and reproduction in HolsteinFriesian cows. Journal of Dairy Science, 90:649-58. DOI:10.3168/ jds.S0022-0302(07)71547-3.

Peel, M.C., Finlayson, B. L., McMahon, T. A., 2007. Updated world map of the Köppen-Geiger climate classification. Hydrology and Earth System Science, 4:439-473.
Robinson, J.J., Ashworth, C.J., Rooke, J.A., Mitchell, L.M., McEvoy, T.G., 2006. Nutrition and fertility in ruminant livestock. Animal Feed Science Technology, 126:259-276. DOI: http://dx.doi.org/10. 1016/j.anifeedsci.2005.08.006.

Rueda, B.L., Blake, R.W., Nicholson, C. F., Fox D.G., Tedeschi, L.O., Pell, A.N., Fernandes, E.C.M., Valentim, J.F., Carneiro, J.C., 2003. Production and economic potentials of cattle in pasture-based systems of the western Amazon region of Brazil. Journal of Animal Science, 81:2923-2937.

Spencer, T.E., Johnson, G.A., Bazer, F.W., Burghardt, R.C., Palmarini, M. 2006. Pregnancy recognition and conceptus implantation in domestic ruminants: roles of progesterone, interferons and endogenous retroviruses. Reproduction, Fertility and Development 19(1) 65-78. DOI: http://dx.doi.org/10.1071/RD06102.

Tinoco, M., Aguilar-Pérez, C.F., León, R.D., Monforte, J.G.M., 2012. Effects of energy supplementation on productivity of dual-purpose cows grazing in a silvopastoral system in the tropics Juan Carlos. Tropical Animal Health and Production, 44:1073-1078. DOI: 10.1007/s11250-011-0042-8.

Viana, J.H.M., Siqueira, L.G.B., Palhão, M.P., Camargo, L.S.A., 2010. Use of in vitro fertilization Technique in the last decade and is Effect on Brazilian Embryo Industry and Animal Production. Acta Scientiae Veterinariae, 38:661-674.

Viana, J.H.M., Siqueira, L.G.B., Palhão, M.P., Camargo, L.S.A., 2012. Features and perspectives of the Brazilian in vitro embryo industry. Animal Reproduction, 9:12-18.

Wathes, D.C., Fenwick, M., Cheng, Z., Bourne, N., Llewellyn, S., Morris, D.G., Kenny, D., Murphy, J., Fitzpatrick, R., 2007. Influence of negative energy balance on cyclicity and fertility in the high producing dairy cow. Theriogenology, 68:232-241. DOI: 10.1016/j.theriogenology.2007.04.006.

Zhu, M.J., Du, M., Hess, B.W., Means, W.J., Nathanielsz, P.W., Ford, S.P., 2007. Maternal nutrient restriction upregulates growth signaling pathways in the cotyledonary artery of cow placentomes. Placenta, 28:361-368. DOI:10.1016/j.placenta.2006.04.005. 